\title{
The mean abnormal result rates of laboratory tests ordered in the emergency department: shooting percentage insights from a multi-centre study
}

\author{
Emeka K. Enwere ${ }^{1} \cdot$ Dongmei Wang $^{2} \cdot$ Maggie Guo $^{3} \cdot$ Christopher Naugler ${ }^{1,3} \cdot$ Eddy Lang $^{2}$
}

Received: 4 May 2020 / Accepted: 21 August 2020 / Published online: 4 January 2021

○ Canadian Association of Emergency Physicians (CAEP)/ Association Canadienne de Médecine d'Urgence (ACMU) 2021

\begin{abstract}
Objective While there is concern about excessive laboratory test ordering in the ED, it is difficult to quantify the problem. One solution involves the Mean Abnormal Result Rate (MARR), which is the proportion of tests ordered that return abnormal results. The primary objective of this study was to calculate MARR scores, and factors associated with MARR scores, for tests ordered between April 2014 and March 2019 at adult EDs in Calgary.

Methods Administrative data were obtained for 40 laboratory tests that met selection criteria. One possible MARR correlate, physician experience, was quantified for $209 \mathrm{ED}$ physicians as number of years since licensure. Analyses were descriptive where appropriate for whole-population data.

Results The condensed dataset comprised 3,395,312 test results on 415,653 unique patients. The aggregate 5-year MARR score was $40.1 \%$. The highest per-test score was for BNP (80.5\%), while the lowest was for glucose (7.9\%). MARR scores were higher for nurse-initiated orders than for physician-initiated orders $(44.7 \%$ vs. $38.1 \%)$. The MARR score correlated inversely with number of tests per order $(r=-0.90 ; 95 \%$ confidence interval $[\mathrm{CI}]-0.65$ to $-0.94 ; p<0.001)$ and directly with physician experience $(r=0.28,95 \%$ CI 0.20 to $0.27 ; p<0.001)$.

Conclusion This is the first study to measure MARR scores in an ED setting. While lower scores (close to 5\%) are less optimal in principle, ideal scores will depend on the clinical context in which tests are used. However, once departmental benchmarks are established, MARR score-monitoring allows efficient tracking of ordering practices across millions of tests.
\end{abstract}

Keywords Laboratory testing $\cdot$ Choosing Wisely $\cdot$ Practice variation $\cdot$ Mean abnormal result rate

\section{Résumé}

Objectifs Bien que l'on s'inquiète d'une commande excessive de tests de laboratoire dans le service d'urgence, il est difficile de quantifier le problème. Une solution implique le taux de résultat anormal moyen (MARR), qui est la proportion de tests commandés qui renvoient des résultats anormaux. L'objectif principal de cette étude était de calculer les scores MARR, et les facteurs associés aux scores MARR, pour les tests commandés entre avril 2014 et mars 2019 dans les services d'urgence pour adultes à Calgary.

Electronic supplementary material The online version of this article (https://doi.org/10.1007/s43678-020-00014-6) contains supplementary material, which is available to authorized users.

Eddy Lang

eddy.lang@ahs.ca

1 Cumming School of Medicine, University of Calgary, Calgary, AB, Canada

2 Department of Emergency Medicine, Cumming School of Medicine, University of Calgary, 3330 Hospital Drive NW, Calgary, AB T2N 4N2, Canada

3 Department of Pathology and Laboratory Medicine, Cumming School of Medicine, University of Calgary, Calgary, AB, Canada 
Les méthodes Des données administratives ont été obtenues pour 40 tests de laboratoire répondant aux critères de sélection. Une corrélation possible du MARR, soit l'expérience des médecins, a été quantifié pour 209 médecins urgentistes en nombre d'années depuis l'autorisation d'exercer. Les analyses étaient descriptives, le cas échéant, pour les données sur l'ensemble de la population.

Résultats L'ensemble de données condensé comprenait 3,395,312 résultats de tests sur 415653 patients uniques. Le score MARR global à 5 ans était de 40,1\%. Le score le plus élevé par test était pour le peptide cérébral natriurétique BNP (80,5\%), tandis que le plus bas était pour le glucose (7,9\%). Les scores de MARR sont plus élevés pour les ordonnances initiées par les infirmières que pour les ordonnances initiées par les médecins $(44,7 \%$ contre $38,1 \%)$. Le score MARR s'est corrélé inversement avec le nombre de tests par ordre $(\mathrm{r}=-0,90$; intervalle de confiance de $95 \%$ [IC] -0.65 to $-0,94 ; p<0.001)$ et directement avec l'expérience du médecin $(r=0.28$, IC à $95 \% 0.20-0.27 ; p<0.001)$.

Conclusions Il s'agit de la première étude à mesurer les scores du MARR dans un contexte de service d'urgence. Bien que des scores inférieurs (près de 5\%) sont moins optimaux en principe, les scores idéaux dépendront du contexte clinique dans lequel les tests sont utilisés. Cependant, une fois les points de repère ministériels établis, la surveillance des scores du MARR permet de suivre efficacement les pratiques de commande sur des millions de tests.

\section{Clinician's capsule}

\section{What is known about this topic?}

There are few robust methods with which to determine if lab test-ordering practices are appropriate across an ED.

What did this study ask?

To what extent do different tests ordered in the ED return abnormal results?

\section{What did this study find?}

Abnormal result rates varied between 8 and $81 \%$, with lower rates suggestive of tests being ordered more often than necessary.

\section{Why does this study matter to clinicians?}

This approach presents a method by which EDs may objectively assess their test-ordering practices over time.

\section{Introduction}

The utility of a laboratory test rests in part on its ability to help rule in or rule out clinical conditions. Nevertheless, many tests are ordered in considerable excess of their clinical utility, leading to increased expense and potential patient harm. The Choosing Wisely guidelines [1] and various other clinical decision rules provide useful guidance in the judicious ordering of tests. These decision rules, however, are of necessity specific to particular clinical contexts. There remains a need for tools with which departmental administrators can quickly screen the thousands or millions of different tests ordered yearly for negative trends in test-ordering practices.
The mean abnormal result rate (MARR) [2] is the proportion of tests ordered which return abnormal results. This simple metric is grounded in the premise that reference ranges often span two standard deviations from the mean, such that $95 \%$ of "healthy" patients will have results that fall within the reference range [3]. The remaining 5\%, which constitutes the baseline MARR for a healthy population, will be expected to have false-positive results [4]. It follows that MARR scores above 5\% demonstrate progressively increasing likelihoods that positive results will be true positives. On this premise, a score near 5\% may indicate over-utilization of a test, wherein it is ordered when not indicated [5]. This metric has been applied to laboratory tests ordered by family physicians in a large metropolitan city [6], but to our knowledge, it has not hitherto been applied to emergency departments.

The primary objective of this study is to apply the MARR metric to assess laboratory test utilization in adult EDs in the Calgary zone, a health region in which overall laboratory test volumes increase at a rate of between 6 and $8 \%$ per year [7]. The goal of this study is to determine MARR metrics for different tests, and to assess other factors which may also influence MARR scores.

\section{Methods}

\section{Study design and setting}

This is a database analysis of results from laboratory tests ordered at adult EDs in Calgary, Alberta between April 1, 2014 and March 31, 2019 (administrative years 2014-2018). The requirement for full ethics review was formally waived by the Conjoint Health Research Ethics Board of the University of Calgary, as this work constitutes a quality assurance activity. Data collection methods, 
tests selected, and other information are detailed in the Supplementary Methods.

\section{Data analysis}

The MARR was calculated using the following equation:

MARR $=\frac{\text { number of abnormal test results }}{\text { total number of test results reported }}$

The initial dataset of approximately 34 million results was consolidated into 3.4 million results for downstream analysis, as shown in Supplementary Fig. 1. A test result was coded as abnormal if it fell outside the reference range. The multiple components of the results of each CBC, blood differential and PT test were consolidated, such that an abnormal result on any single component constituted an abnormal result for the entire test. Exact durations of patient visits were not available, and so a duration in excess of the 90th percentile of duration-of-stay in this department ( $26 \mathrm{~h}$ ) was set as the upper limit. As the goal was to determine MARR scores from initial orders for a test, repeat orders were excluded from analysis.

\section{Statistical analysis}

As the data represented an entire population rather than a sample, descriptive statistics were used where appropriate. The Pearson correlation coefficient was used to evaluate the relationship between number of tests per order and MARR score. Repeated measures correlation [8] was used to assess the relationship between the number of years since physician licensure and the physicians' MARR scores. Confidence intervals for the repeated measures correlation were determined using bootstrapping of 300 samples. Analyses were performed using R statistical software, version 3.5.3 (R Foundation for Statistical Computing, Vienna, Austria) on the High Performance Computing cluster of the University of Calgary.

\section{Results}

Additional results are available in the data supplement. The dataset comprised 33,757,004 results from 40 laboratory tests performed on 415,665 patients. Following the removal of qualitative results, consolidation of multi-component test results, and the removal of repeat orders, 3,395,312 results for 415,653 patients were available for further analysis. These were the outcomes of 836,414 patient visits and $1,236,858$ test requisitions. Of these results, $69.8 \%$ were the outcomes of physician-initiated orders (ED physicians and those of other specialties), with the remainder being nurse-initiated orders (Supplementary Fig. 1). The aggregate MARR score for all EDs over the 5-year study period was $40.1 \%$, indicating that approximately $40 \%$ of tests ordered returned abnormal results.

To determine the extent to which individual tests contributed to overall MARR, we identified tests with the highest and lowest MARR scores. We also calculated MARR scores for physician- and nurse-initiated orders. For tests that were ordered at least 1,000 times over the study period, BNP and serum glucose had the highest and lowest (Table 1 and Supplementary Fig. 2) overall MARR scores (80.5 and 7.9\%, respectively). Nurse-initiated orders had a higher 5-year aggregate MARR score (44.7\%) than physician-initiated orders (38.1\%).

We examined the number of tests per order requisition, and physician practice experience, as factors that may be associated with MARR scores. The MARR score correlated

Table 1 Highest and lowest per-test MARR scores

\begin{tabular}{|c|c|c|c|c|c|c|c|c|}
\hline \multicolumn{3}{|l|}{ Total } & \multicolumn{3}{|c|}{ Physician-initiated orders } & \multicolumn{3}{|c|}{ Nurse-initiated orders } \\
\hline Test & MARR & $\%$ of total tests & Test & MARR & $\%$ of total tests & Test & MARR & $\%$ of total tests \\
\hline BNP & 80.5 & 0.8 & $\mathrm{BNP}$ & 80.5 & 1.2 & $\mathrm{CBC}$ & 62.3 & 38.9 \\
\hline $\mathrm{CBC}$ & 62.6 & 24.3 & $\mathrm{CBC}$ & 62.9 & 18.1 & Osmolality & 59.1 & 2.5 \\
\hline Osmolality & 58.2 & 1.7 & Osmolality & 57.5 & 1.3 & $\mathrm{PT}$ & 47.3 & 2.8 \\
\hline CSF cell count & 56.9 & 0.1 & CSF cell count & 57.0 & 0.2 & Blood differential & 37.2 & 37.7 \\
\hline Ammonia & 54.2 & 0.2 & Ammonia & 54.2 & 0.2 & PTT & 30.0 & 0.7 \\
\hline Glucose & 7.9 & 2.0 & Glucose & 10.2 & 1.7 & Glucose & 4.4 & 2.7 \\
\hline Sodium & 11.6 & 0.9 & Magnesium & 13.0 & 6.1 & Sodium & 10.2 & 2.5 \\
\hline Magnesium & 13.0 & 4.3 & Lipase & 17.8 & 1.2 & Creatinine & 13.4 & 0.2 \\
\hline Lipase & 17.6 & 0.9 & Bilirubin (total) & 18.4 & 2.0 & Magnesium & 14.2 & 0.1 \\
\hline Bilirubin (total) & 18.3 & 1.4 & Calcium & 20.2 & 5.5 & ALP & 14.2 & 0.1 \\
\hline
\end{tabular}

Data are only reported for the top and bottom 5 tests for which at least 1000 results were available. Data for the remaining tests are in the data supplement 
inversely with the number of tests per requisition $(r=-0.90$; 95\% Confidence Interval $[\mathrm{CI}]-0.66$ to $-0.94 ; p<0.001$; Supplementary Fig. 3), with MARR score decreasing by approximately $1.9 \%$ per extra test added. The number of years since licensure was used as a proxy for practice experience. Among ED physicians, there was a modest but significant correlation between number of years since licensure and MARR $(r=0.28$; 95\% CI 0.20 to $0.27 ; p<0.001$; Supplementary Fig. 4), with MARR score increasing by approximately $1.4 \%$ per decade of experience. Similar data were not available for residents or non-ED physicians.

\section{Discussion}

In this multicenter database analysis of laboratory tests ordered out of EDs in Calgary, we demonstrate the first use of the MARR to assess test-ordering practices in the ED. Our study uncovered considerable differences in MARR scores of individual tests, and between nurse- and physicianinitiated orders. As previous studies have highlighted large numbers of tests per order [9] and physician experience [10] as factors in inappropriate lab test ordering, it is not unreasonable to infer that the correlation of these factors with MARR scores is significant.

At the departmental level, MARR score data may help direct critical downstream questions, such as: (a) Are tests with low scores (close to the theoretical minimum of 5\%) being ordered excessively? (b) Are tests with high scores (close to the theoretical maximum of 100\%) being ordered insufficiently? That is, are there patients for whom tests are indicated but who were untested? (c) Do changes in a test's MARR score over time highlight potentially significant changes in ordering behaviors for that test?

\section{Limitations}

It was necessary to impute the duration of a patient visit from departmental averages. This study also did not address, nor was it possible for such a study to address, the clinical decision-making processes that underlay the decision to order each test. Furthermore, the definitions of "abnormal" applied in calculation of the MARR metric were strictly based on the upper and lower limits of normal established in this department. We acknowledge that results slightly outside these limits may not be clinically significant. Finally, the centers included in this study make use of preset order panels, which may unfavorably decrease the MARR scores of some tests.

\section{Conclusions}

The MARR score, as presented here, is an administrative tool to help identify test-ordering practices that may be excessive or insufficient. It is not a point-of-care tool, as it does not account for clinical context. The specific per-test MARR score cut-offs would have to be determined from future studies; however, once there are benchmarks associating optimal test-ordering practices with particular MARR scores, the metric becomes a tool to monitor these practices over time.

Acknowledgements We thank Shawn Dowling, MD for a critical review of this manuscript, and Zane Ramdas and Patricia Johnson for assistance with data collection.

Funding This research received no specific grant from any funding agency, commercial or not-for-profit sectors.

\section{Compliance with ethical standards}

Conflict of interest The author(s) declare that they have no competing interests.

\section{References}

1. Baird GS. The Choosing Wisely initiative and laboratory test stewardship. Diagnosis (Berlin Germany). 2019;6(1):15-23.

2. Naugler CT, Guo M. Mean abnormal result rate: proof of concept of a new metric for benchmarking selectivity in laboratory test ordering. Am J Clin Pathol. 2016;145(4):568-73.

3. Katayev A, Balciza C, Seccombe DW. Establishing reference intervals for clinical laboratory test results: is there a better way? Am J Clin Pathol. 2010;133(2):180-6.

4. Naugler C, Ma I. More than half of abnormal results from laboratory tests ordered by family physicians could be false-positive. Can Fam Physician. 2018;64(3):202-3.

5. Zhi M, Ding EL, Theisen-Toupal J, Whelan J, Arnaout R. The landscape of inappropriate laboratory testing: a 15-year metaanalysis. PLoS ONE. 2013;8(11):e78962.

6. Brack AP, Guo M, Ma I, Naugler C. Use of the mean abnormal result rate (MARR) to gauge changes in family physicians' selectivity of laboratory test ordering, 2010-2015. Am J Clin Pathol. 2017;148(5):436-40.

7. Naugler C. A perspective on laboratory utilization management from Canada. Clin Chim Acta. 2014;427:142-4.

8. Bakdash JZ, Marusich LR. Repeated measures correlation Front Psychol. 2017;8:456.

9. Fillée C, Beguin C, Habimana L, Hubert C, Philippe M. How to optimize the prescription of laboratory tests? Success and failures in an academic hospital. Scand J Clin Lab Investig. 2018;78(3):197-203.

10. van Walraven $C$, Naylor $C D$. Do we know what inappropriate laboratory utilization is? A systematic review of laboratory clinical audits. JAMA. 1998;280(6):550-8. 